\title{
A short, intensive cognitive behavioral pain management program reduces health-care use in patients with chronic low back pain
}

\author{
Two-year follow-up results of a prospective cohort
}

\author{
Miranda L. van Hooff • Werner ter Avest • Philip P. Horsting • John O'Dowd • \\ Marinus de Kleuver · Wim van Lankveld · Jacques van Limbeek
}

Received: 22 April 2011/Revised: 29 September 2011/Accepted: 14 November 2011/Published online: 3 December 2011

(C) The Author(s) 2011. This article is published with open access at Springerlink.com

\begin{abstract}
Purpose Cognitive behavioral interventions are recommended as non-invasive treatment options for patients with chronic low back pain (CLBP). However, most treatment effects are small and short-lived. Although a 2-week intensive pain management program for patients with CLBP seems to be effective, the long-term results are not known. The purpose of this study is to evaluate the stability of the 2-year follow-up results and whether this is reflected in the use of health-care services.

Methods A prospective cohort study was performed. Pretreatment characteristics of patients and data of outcomes obtained at 1-year follow-up were used. At 2-year followup a structured interview was conducted following the principles of a post-marketing survey. Outcomes included daily functioning, quality of life, current intensity of pain, disturbance of pain during daily activities, and indicators of the use of pain medication and health-care services.

Results Of the 90 eligible patients 85 (94\%) participated in the post-marketing survey. The 1-year clinical relevant effects are maintained at 2-year follow-up. Effect sizes for functioning and quality of life were large. More than $65 \%$
\end{abstract}

M. L. van Hooff $(\bowtie)$. W. ter Avest · W. van Lankveld .

J. van Limbeek

Department Research Development and Education,

Sint Maartenskliniek, P.O. Box 9011,

6500 GM Nijmegen, The Netherlands

e-mail: m.vanhooff@maartenskliniek.nl

P. P. Horsting - M. de Kleuver

Department of Orthopedics, Sint Maartenskliniek,

P.O. Box 9011, 6500 GM Nijmegen, The Netherlands

J. O'Dowd

The RealHealth Institute, 23-31 Beavor Lane,

London W6 9AR, UK reached preset minimal clinically important differences. At pre-treatment all patients consulted their general practitioner (GP) and medical specialist (MS). At 2-year followup 73\% reported having consulted neither a GP nor an MS during the previous year. Most of the patients indicated not to use any pain medication $(57 \%)$ and the percentage patients using opioids have decreased (14\%). Moreover, $81 \%$ reported to be at work.

Conclusions The gained results from selected and motivated patients with longstanding CLBP at 1-year follow-up are stable at 2-year follow-up. Above all, most of the participants are at work and results indicate that the use of both pain medication and health care have decreased substantially.

Keywords Chronic low back pain - Health-care services . Cognitive behavioral program - Pain management .

Daily functioning

\section{Introduction}

Low back pain is one of the most common disabling conditions and causes high health expenditure in developed countries [1-3]. This condition has a high prevalence: over $70 \%$ of the adult population experience at least one episode of low back pain $[1,4-6]$. In the Netherlands the annual prevalence in 2003 was approximately $44 \%$ [1]. A minority (20\%) develop chronic low back pain (CLBP), meaning that the complaints persist at least 3 months [2] and are associated with persistent or recurrent disability. These complaints may result in the individuals experiencing a lower health-related quality of life; they cause a quarter of all sick leave in the employed population $[1,3,4]$. The Dutch National Institute for Public Health and the 
Environment (RIVM) estimated CLBP-related costs to be $0.9 \%$ of total health-care costs in the Netherlands [5], resulting in its being the top three of the highest health-care costs [6]. Moreover, $14 \%$ of the adult population with a disability allowance in the Netherlands is diagnosed with CLBP. Therefore, CLBP is not only a burden for the patient but the related health-care costs are also a problem for society.

A wide range of interventions to manage CLBP are used including pharmaceutical, surgical, and non-surgical interventions [3, 7, 8]. However, many commonly used interventions lack evidence of clinically relevant longterm effects [4]. International guidelines [9-11], a Cochrane review [12] as well as recently performed randomized controlled trials have demonstrated that a cognitive behavioral approach most effectively reduces disability in CLBP patients [8, 13-15]. Nevertheless, most effects achieved by these non-invasive treatments are small and short-lived [14, 16-18]. A systematic review with 1964 randomly allocated patients concluded that $100 \mathrm{~h}$ or more of intensive, multidisciplinary rehabilitation with a functional restoration approach including cognitive behavioral interventions reduces pain and improves functionality [19]. Furthermore, most reported treatment programs have a mean duration of 4 weeks [18, 20] or more [8, 13-15].

A recently published study by van Hooff et al. [21] evaluated the 1 year results of a cohort of patients, who participated in a 2 -week program provided by RealHealth NL. The program is based on cognitive behavioral principles and aims at improving daily functioning by selfmanagement of lower back pain complaints. Participants with longstanding CLBP complaints (12 years on average) learned to manage CLBP, improved fast in daily functioning, and experienced a fast improvement in their quality of life. These results were meaningful and clinically relevant to the participants and comparable to results after spinal surgery and superior to results for rehabilitation programs of longer duration. However, the question remains whether these positive short-term effects are sustained in the long run and whether these benefits are reflected in the degree of health-care use and the use of pain medication.

Therefore, in this study the main purpose is to evaluate the stability of the 2-year (long-term) follow-up results of a short, intensive cognitive behavioral pain management program provided by RealHealth NL. The emphasis is on evaluating daily functioning, the use of health-care services, and pain medication 2 years after the intervention. We hope that improvements gained in the first year (shortterm) will be maintained and the use of health-care services and pain medication will be reduced in the second year of follow-up.

\section{Materials and methods}

\section{Study design and setting}

This study is an extension of a prospective cohort study in which the effectiveness of an intensive cognitive behavioral pain management program was evaluated after 1 year of follow-up [21]. We used data obtained by questionnaire at pre-treatment, including patient characteristics, outcome measures and indicators of health care, and pain medication use. Outcome assessments performed at 1 year after treatment yielded the primary outcome measure and heathrelated quality of life (Short-Form 36). These outcomes were compared with outcome assessments at the 2-year follow-up. To achieve a high response rate a structured interview following the principles of a post-marketing survey was added to obtain data at 2-year follow-up. During this interview, the same questionnaires were used as those completed at pre-treatment. A short description of participants, treatment, and outcome measures follows.

\section{Patients and treatment}

A detailed description of participants and treatment has been reported previously [21]. Patients entered the study consecutively. The main inclusion criteria for the intervention were low back pain for at least 6 months, no indication for surgical or other invasive pain treatment confirmed by spinal surgeons at the Sint Maartenskliniek, no intention of seeking medical treatment in the year following the 2-week program, age between 20 and 65 years, motivation to change behavior, willing to follow the program and to reside in a hotel for 2 weeks, able to speak and read Dutch. The main exclusion criterion was psychiatric disorders.

The evidence-based, intensive cognitive behavioral pain management program was developed by the RealHealth Institute in the United Kingdom and follows published international guidelines [9-11]. In the Netherlands all sessions are delivered by the trainers of the RealHealth multidisciplinary team. The team consists of a psychologist, a physiotherapist, and an occupational therapist. The full program comprises an assessment day for intake, the 10 day residential program with two follow-up days: 1-month and 1-year post-treatment. The main aim of the intervention is to improve daily functioning. This is achieved by increasing the capability to self-manage the CLBP complaints. The program consists of $100 \mathrm{~h}$ of participant contact time, approximately $50 \mathrm{~h}$ of cognitive behavioral training, $35 \mathrm{~h}$ of graded physical activities, and $15 \mathrm{~h}$ of education in which the cognitive behavioral principles are integrated. The program is delivered in a 2-week, group-orientated residential setting. 
Outcome assessment: procedure

Participants who had completed the 1-year follow-up were contacted. All recruited respondents were telephoned by a secretary and were asked if they were willing to participate in a follow-up study, including a telephone survey at a later time. When the respondent consented, the secretary made the appointment for a telephone call; the questionnaire booklet as well as a background information sheet was sent. The participants completed the questionnaire at home without assistance. The questionnaires are described in the "Outcome measures" section, which included daily functioning, health-related quality of life, different pain scales, and questions about use of health-care services, pain medication, and return-to-work. An independent researcher (W ter A) conducted the 20-min standardized telephone interviews in the period March-June 2010. During the telephone interview, the answers of the questionnaires were passed without any discussion. A small gift voucher for flowers as a present for participation was sent after the interview was completed.

Outcome measures

\section{Primary outcome}

Roland and Morris Disability Questionnaire (RMDQ) The RMDQ [22] contains 24 questions and measures functional disability in patients with low back pain [8, 22]. The total score ranges between 0 (no disability) and 24 (maximal disability).

\section{Secondary outcomes}

Short-Form 36 Health Survey Questionnaire (SF36) The SF36 [23] is a generic instrument to measure the healthrelated quality of life. The validated Dutch language version has been used in a wide range of studies among patients with chronic health conditions including CLBP [24]. The instrument contains 36 items in 8 subscales. The subscales results were combined into two summary scores: the SF36 Physical Component Score (SF36 PCS) and the SF36 Mental health Component Score (SF36 MCS).

Health-care use Indicators for health-care use were consultation of a general practitioner (GP) or a medical specialist (MS) and referral to a physical therapist (PT) or a psychologist (PS) during the previous 12 months as well as current pain medication consumption (analgesics). Patients were asked to provide information before the program and at 2-year follow-up. Consultation and referral questions were scored on a dichotomous scale (yes/no), which in addition to information about the frequency of these visits yielded an impression of the program's impact on healthcare use. Pain medication was classified in accordance with the three-step World Health Organization (WHO) analgesic ladder. These steps are (1) non-opioid analgesics with adjuvant therapy when needed, (2) an addition of a weak opioid, and (3) a strong opioid addition to non-opioid and adjuvant therapy [25]. For this study, the first step was split into two categories: (1A) paracetamol also known as acetaminophen in the USA and (1B) non-steroidal antiinflammatory drugs (NSAIDs). Pain medication was then classified as: 'none-light' (none and WHO-step 1A) and 'moderate-severe' (WHO-steps 1B-3). The 'none/light' classification indicates analgesics which have no or only few side effects [3, 16, 26]. The analgesics in the 'moderate-severe' classification are known to have adverse side effects, especially when used for a long period [3]. Furthermore, we classified consumption of analgesics as being 'structural' (daily) and 'incidental' (only when needed or less than once a week).

\section{Tertiary outcome}

Visual analogue scales for pain to measure current intensity and disturbance during daily activities (VAS 'current intensity' and VAS 'disturbance $A D L$ ') Participants were asked about the current intensity of their back pain for the day of the questionnaire and about the disturbance of back pain during daily activities. Both severity and disturbance were marked on a line of $100 \mathrm{~mm}$, with $0 \mathrm{~mm}$ indicating 'no pain' and $100 \mathrm{~mm}$ 'unbearable pain' [27, 28].

Statistical analysis

Frequencies of characteristics assessed at pre-treatment and health-care use are described. To compare the characteristics of non-responders, an independent Student's $t$ test was performed for the pre-treatment characteristics and the outcome measures. Maintenance of gained results at 2-year follow-up for all outcomes, except for health-care use, was calculated with a paired samples Student's $t$ test.

To explore clinical relevance, we calculated effect sizes (Cohens' $d$ ) for primary and secondary outcomes (RMDQ and SF36 PCS) to indicate the magnitude of treatment effect for the RealHealth program. This measure is defined as the difference between the means of the pre-treatment assessment and of the 2-year follow-up divided by the pooled standard deviation. An effect size $(d)$ of 0.2 is considered to be small, 0.5 moderate, while 0.8 indicates a large effect [29]. Moreover, an effect size $(d)$ of 1 is equivalent to a change of 1 standard deviation in the study sample.

All statistical analyses were conducted using SPSS, version 17.0 for Windows. We set the level of significance 
at 0.05 . Pie charts to present frequencies are created in STATA version 10.0 .

\section{Results}

Response

In March 2010, we had complete data sets available for 90 participants $(84 \%)$, who were eligible to be contacted for the 2-year follow-up. A total of five patients were seen as non-responders, either because they could not be reached in time (three patients) or was in final stage of illness and had other priorities (one patient) or wished not to co-operate (one patient). These five non-responders were not significantly different to the included participants with regard to pre-treatment characteristics and outcome measures: RMDQ, SF36, and both VAS scales ('current intensity' and 'disturbance ADL'). A total of 85 participants (94\%) joined in the post-marketing survey at 2-year follow-up.

\section{Patient characteristics}

Table 1 shows the demographics of the 85 participants. They reported longstanding CLBP (11 years on average) and $29 \%$ had an earlier surgery for their back problem.

\section{Clinical outcome}

In Table 2 outcome measures are presented except those for health-care use. Between 1- and 2-year follow-up assessments the mean scores remained stable. Only pain 'disturbance of ADL' significantly improved between 1and 2-year follow-up: $d f(1,84), t=2.57, p=0.01$. In Fig. 1 the trends, means with $95 \%$ confidence intervals for the primary outcome 'functional disability' as measured with the RMDQ, are graphically presented.

Health-care use

At the pre-treatment assessment all participants reported to have consulted their general practitioner (GP) for their back problem, at least once in the past year, and all of them were referred to a medical specialist (MS; i.e., orthopedic surgeon, neurologist, pain consultant, rheumatologist, physiatrist, or anaesthesiologist). Furthermore, at pretreatment assessment $48 \%$ of the participants $(n=41)$ had consulted at least two different MS in the previous year. At 2-year follow-up only a quarter of all participants, $27 \%$ $(n=23)$ reported having consulted their GP in the last year and 14 of these 23 consulted an MS just once. The remaining $73 \%$ consulted neither a GP nor an MS in that year.

At the pre-treatment assessment most of the participants (94\%; $n=80$ ) indicated to have had physical therapy for their back problem in the previous year. In addition, $15 \%$ ( $n=13$ ) visited a psychologist. At 2-year follow-up the allied health-care visits have considerably decreased, 29\% $(n=24)$ reported to have had physical therapy and only $1 \%(n=1)$ consulted a psychologist for their back painrelated problems in the last year.

Medication use decreased from $87 \%(n=74)$ at baseline to $43 \%(n=37)$ at 2-year follow-up. At pre-treatment assessment $68 \%$ of the participants $(n=58)$ used

Table 1 Pre-treatment demographics and 2-year follow-up results of return-to-work as reported by the participants $(n=85)$

\begin{tabular}{|c|c|c|}
\hline Demographics & $n=85$ & \\
\hline \multicolumn{3}{|l|}{ Sociodemographic } \\
\hline Age, mean $(\mathrm{SD}$, range min-max) in years & $42.9( \pm 8.4,23-60)$ & \\
\hline \multirow[t]{2}{*}{ Gender $n(\%)$, male:female } & $35(41 \%): 50(59 \%)$ & \\
\hline & Pre-treatment assessment & 2-year follow-up \\
\hline \multicolumn{3}{|l|}{ Work status $n(\%)$} \\
\hline Yes:no & $57(68 \%): 28(32 \%)$ & $69(81 \%): 16(19 \%)$ \\
\hline At work-full time & $31(37 \%)$ & $32(38 \%)$ \\
\hline At work-part time & $26(31 \%)$ & $37(44 \%)$ \\
\hline Unemployed because of CLBP & $13(15 \%)$ & $8(9 \%)$ \\
\hline Unemployed because of other causes & $4(5 \%)$ & $3(4 \%)$ \\
\hline Disability pension & $11(13 \%)$ & $5(6 \%)$ \\
\hline \multicolumn{3}{|l|}{ CLBP history } \\
\hline Duration of LBP, mean (SD, range min-max) in years & $12.2( \pm 11.3,1-51)$ & \\
\hline Previous surgery $n(\%)$ yes:no & $25(29 \%): 60(71 \%)$ & \\
\hline
\end{tabular}


Table 2 Mean (SD) for outcome measures at 1- and 2-year follow-up with $t$ values for paired comparisons and significance levels $(n=85)$

\begin{tabular}{lccc}
\hline & 1-year FU & 2-year FU & $t$ value \\
\hline $\begin{array}{l}\text { Primary outcome } \\
\text { RMDQ }\end{array}$ & $7.5(5.0)$ & $7.2(5.0)$ & 0.75 \\
Secondary outcomes & & & 0.45 \\
$\quad$ SF36 PCS & $64.6(17.8)$ & $65.9(20.6)$ & -0.50 \\
SF36 MCS & $70.9(15.2)$ & $71.9(17.1)$ & -0.52 \\
Tertiary outcomes & & & 0.62 \\
VAS 'current intensity' & $35.9(23.4)$ & $35.0(27.5)$ & 0.96 \\
VAS 'disturbance in ADL' & $35.3(26.9)$ & $27.1(27.1)$ & 2.57 \\
\hline
\end{tabular}

FU follow-up, RMDQ Roland and Morris Disability Questionnaire, SF36 PCS Short Form 36 Physical Component Scale, SF36 MCS Short Form 36 Mental Component Scale, VAS visual analogue scale, with 'current intensity' indicating pain severity and 'disturbance in ADL' indicating disturbance of pain during daily activities

$* p<0.05$

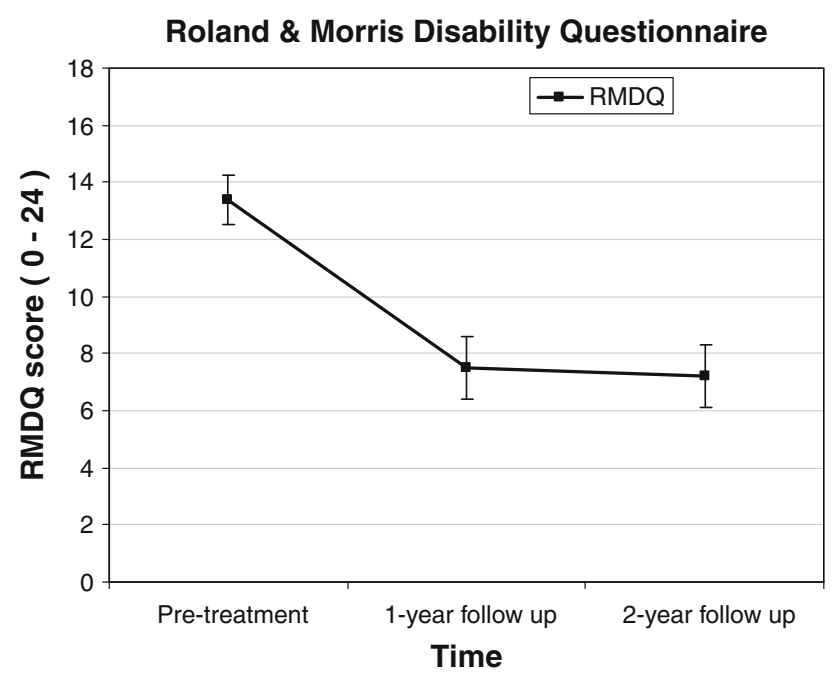

Fig. 1 Roland and Morris Disability Index (RMDQ); means and 95\% confidence intervals. Trend of maintenance of gained results between 1- and 2-year follow-up

analgesics for their back problem on a structural basis, while $13 \%(n=11)$ did not use any pain medication. The pie charts in Fig. 2 show the frequencies of analgesic consumption as classified in WHO analgesic ladder both at pre-treatment and at 2-year follow-up. At 2-year follow-up the 'none-light' consumption group has increased to almost three quarters of the participants $(n=60 ; 71 \%)$, while the 'moderate-severe' group has decreased to $29 \%$ $(n=25)$.

\section{Clinical relevance}

The effect size (Cohens' $d$ ) for functioning (RMDQ) is 1.6 and for functioning-related quality of life (SF36 PCS) is 1.4. The effect sizes of both measures were larger than 1 and, therefore, classified as 'large'.
These results were further substantiated by data related to work status as presented in Table 1. At 2-year follow-up, $81 \%$ of all participants reported being at work. Eight of the 13 participants who had reported at pre-treatment assessment being unemployed because of their back problem were working 2 years after the treatment. Moreover, 5 out of 11 participants who received a disability allowance at baseline indicated having returned to work.

\section{Discussion}

The main purpose of this study was to evaluate the 2-year follow-up results of the cognitive behavioral pain management program offered by RealHealth NL in patients with CLBP. We questioned whether improvements gained in the first year would be maintained and whether this would be reflected in the use of pain medication and healthcare services. Patients in our study population appeared to have a mean baseline level of functioning as measured with RMDQ $(13 \pm 4)$. This level is indicative for a moderate to severe level of disability, which is comparable to patients being treated in other trials and daily practice in the Netherlands $[8,21]$. In this study, we confirmed that the previously reported 1-year clinically relevant effects on daily functioning and quality of life were maintained at the 2-year follow-up. Participants even reported experiencing less pain while performing activities; this decrease was statistically significant. Moreover, health-care use (i.e., GP, MS consultations and pain medication use at 2-year followup) decreased between baseline and 2-year follow-up assessment. Positive outcomes of the intervention were further corroborated by work status data. Most of the participants returned to work, with $81 \%$ actually working at the 2-year follow-up. These results suggest that patients who participated managed to incorporate the learned self- 
Fig. 2 Pie charts illustrating percentages of participants $(n=85)$ who use pain medication, classified in accordance with the steps in WHO analgesic ladder [25] and differentiated in consumption groups: 'none-light' (green) and 'moderate-severe' (red)

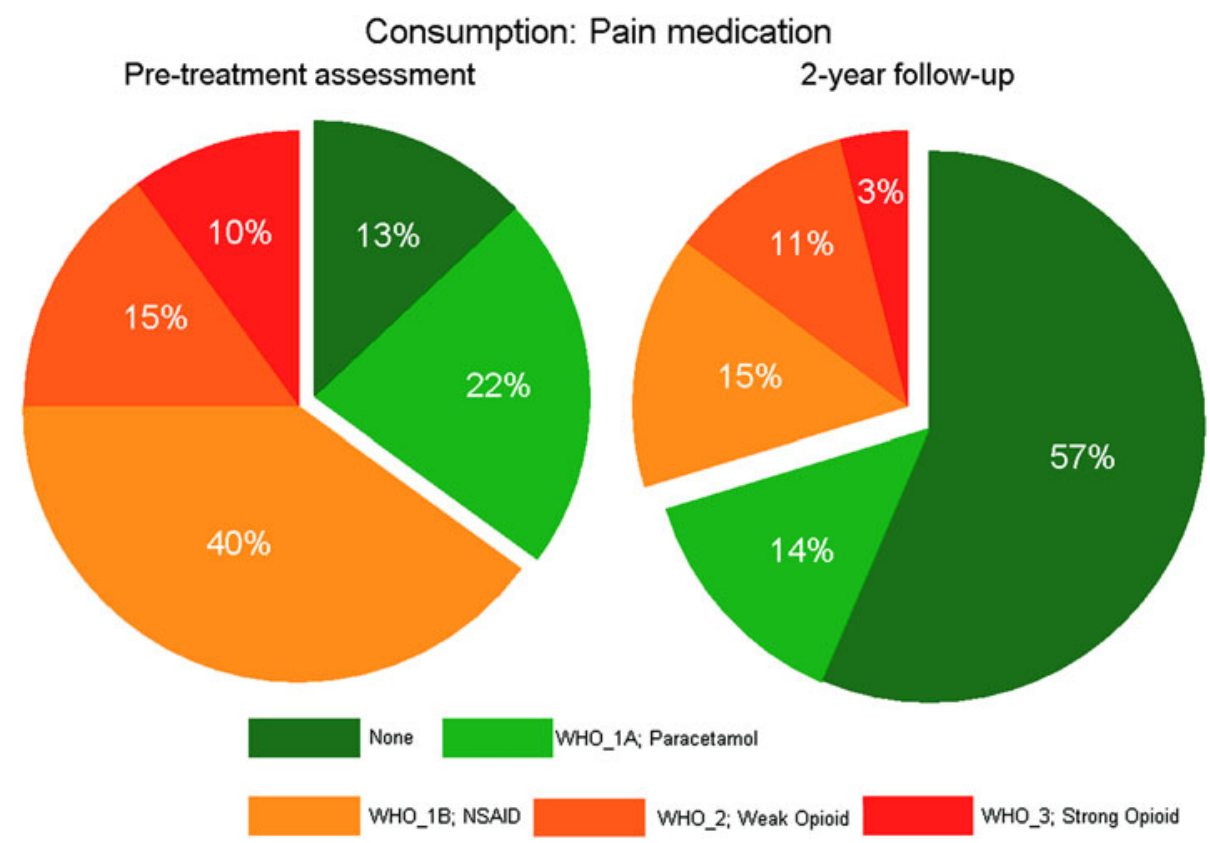

management techniques in daily life and that they changed their occupational and social behavior.

Many commonly used interventions lack evidence for the maintenance of clinically relevant long-term effects [4]. This study shows large effect sizes (Cohens' $d=1.4-1.6$ ). Although we had five non-responders in the current study, they did not differ in patient characteristics and outcomes at baseline to the included patients. Their drop out was not related to either the treatment program or the study itself. Therefore, it is noteworthy that patients with longstanding CLBP complaints, 11 years on average, benefit from this short and intensive pain management program which is based on international guidelines [9-11]. Post hoc analyses revealed that no significant correlations existed between duration of CLBP and change in outcome measures at 1-year follow-up (RMDQ $r=0.05$; SF36PCS $r=0.07$; current pain $r=0.13$; pain disturbance ADL $r=0.09$ ) and at 2-year follow-up (RMDQ $r=0.02$; SF36PCS $r=0.08$; current pain $r=0.15$; pain disturbance ADL $r=0.09$ ). The current study results suggest that the duration of CLBP is not an important factor for the management of CLBP, whereas duration and intensiveness of the program are important [7, 12, 21].

It is known that CLBP accounts for considerable health care and socioeconomic costs $[5,6,14]$. These health-care costs are, among other things, related to sick leave and disability allowance, referrals to general practitioners and medical specialists, use of allied health care and pharmaceutical prescriptions for analgesics. Therefore, we evaluated health-care use on all of these dimensions of health-care costs. The results of this study show that healthcare use is decreased at long-term follow-up. A marked reduction of analgesic use is seen and a shift of most patients is shown from the 'moderate-severe' (WHO-steps $1 \mathrm{~B}-3 ; 65 \%$ ) to the 'none-light' (none and WHO-step 1A; $71 \%$ ) category of the WHO analgesic ladder. Moreover, with a reduction in analgesic use a decrease of pain intensity and pain experience during daily activities (VAS scores) is shown, as well as maintenance of these results at 2-year follow-up. In patients with CLBP antidepressants are sometimes prescribed for pain reduction [selective serotonin reuptake inhibitors (SSRI) and tricyclic antidepressants (TCA)]. We found at baseline that only $11 \%$ used antidepressants (4\% TCA and 7\% SSRI) and at long-term followup a reduction in consumption is seen: only two respondents (2\%) reported to use this medication (2\% TCA and none used SSRI). This implies that the program is successful not only on health-care use with a reduction in health-care costs, but also on safety possibly resulting in less adverse side effects. When the results are extrapolated to the Dutch adult population a quarter of the patients with CLBP could benefit from this program and therefore an estimated half of the health-care costs could be saved.

\section{Limitations of the study}

This study has some limitations. The external validity of the study might be limited, depending to whom the results are generalized. Since we studied a prospective cohort with carefully selected patients over a period of time, we have to restrict the generalization to patients with similar characteristics. The patients included had no indication for a surgical intervention and they had to confirm that they were motivated to change their behavior with regard to the back 
pain complaints. Therefore, generalization to the general population is limited.

We evaluated health-care use by means of self-reported questionnaires and, therefore, bias could have been introduced. We took this aspect into account in the design of the study, a structured post-marketing survey, and by asking the participants to request additional information at general practitioner or pharmacy if necessary. A possible bias could have been introduced due to the fact that patients had to recall what happened in the last year.

The intervention described in this study uses a wide range of techniques based on principles of CBT. As yet it is unclear which techniques, or parts of the intervention are responsible for the observed effect. Therefore, we studied the intervention as an integral program. The main aim of the study was to evaluate the stability of positive outcomes of a short, intensive intervention and its impact on health-care use. Therefore, we did not evaluate frequently reported cognitive and behavioral factors as fear of movement, catastrophizing, and anxiety [4, 30-32]. These cognitive behavioral factors contribute, among other factors, to a certain extent to the main outcome functioning and quality of life. We showed a long-term significant improvement on the mental component scale of the SF36, but a closer exploration of these cognitive behavioral factors and their impact on functionality is needed. Moreover, patients attending this program have to be motivated to change their behavior. Although a selection criterion for treatment, we neither assessed this factor in a clear valid and reproducible way at pre-treatment nor assessed it systematically over time. Therefore, a clear description of 'motivation to change behavior' in the subgroup of CLBP patients benefitting from this program cannot be given. 'Readiness or motivation to change pain-related behavior' is a multidimensional construct recently described in the literature [33, 34]. As individuals may vary in their readiness to learn and adopt new coping skills or self-management strategies it may be a key element in understanding how participants benefit or fail to benefit from this program.

\section{Conclusion}

In a selected and motivated group of patients with longstanding CLBP, the results of a short intensive cognitive behavioral pain management program gained in the first year are maintained at the 2-year follow-up. Above all, at follow-up most of the participants are at work, they perform a gainful employment, and the results suggested that the use of both pain medication and health care have decreased substantially.
Acknowledgments The authors thank Mrs. P. G. Anderson for her editorial comments.

\section{Conflict of interest None.}

Open Access This article is distributed under the terms of the Creative Commons Attribution Noncommercial License which permits any noncommercial use, distribution, and reproduction in any medium, provided the original author(s) and source are credited.

\section{References}

1. Picavet HS, Schouten JS (2003) Musculoskeletal pain in the Netherlands: prevalences, consequences and risk groups, the DMC(3)-study. Pain 102:167-178

2. Frymoyer JW (1992) Predicting disability from low back pain. Clin Orthop Relat Res 101-109

3. Cohen SP, Argoff CE, Carragee EJ (2008) Management of low back pain. BMJ 337:a2718

4. Koes BW, van Tulder MW, Thomas S (2006) Diagnosis and treatment of low back pain. BMJ 332:1430-1434

5. Picavet HS (2005) Aspecifieke lage rugklachten: omvang en gevolgen. Chronische Ziekten RIVM Centrum voor Preventie- en Zorgonderzoek PZO 1-8

6. Meerding WJ, Bonneux L, Polder JJ, Koopmanschap MA, van der Maas PJ (1998) Demographic and epidemiological determinants of healthcare costs in Netherlands: cost of illness study. BMJ 317:111-115

7. Guzman J, Esmail R, Karjalainen K, Malmivaara A, Irvin E, Bombardier C (2002) Multidisciplinary bio-psycho-social rehabilitation for chronic low back pain. Cochrane Database Syst Rev CD000963

8. Smeets RJ, Vlaeyen JW, Hidding A, Kester AD, van der Heijden GJ, Knottnerus JA (2008) Chronic low back pain: physical training, graded activity with problem solving training, or both? The one-year post-treatment results of a randomized controlled trial. Pain 134:263-276

9. Airaksinen O, Hildebrandt J, Mannion AF, Ursin H, Brox JI, Klaber-Moffett J, Reis S, Zanoli G, Cedraschi C, Kovacs F, Staal JB (2004) European Guidelines for the management of chronic non-specific low back pain. Working Group on Guidelines for Chronic Low Back Pain

10. Chou R, Loeser JD, Owens DK, Rosenquist RW, Atlas SJ, Baisden J, Carragee EJ, Grabois M, Murphy DR, Resnick DK, Stanos SP, Shaffer WO, Wall EM (2009) Interventional therapies, surgery, and interdisciplinary rehabilitation for low back pain: an evidence-based clinical practice guideline from the American Pain Society. Spine (Phila Pa 1976) 34:1066-1077

11. National Institute for Health and Clinical Excellence (2009) Low back pain: early management of persistent non-specific low back pain. National Collaborating Centre for Primary Care, London (NICE Clinical Guideline 88)

12. Ostelo RW, Deyo RA, Stratford P, Waddell G, Croft P, Von KM, Bouter LM, de Vet HC (2008) Interpreting change scores for pain and functional status in low back pain: towards international consensus regarding minimal important change. Spine 33:90-94

13. Johnson RE, Jones GT, Wiles NJ, Chaddock C, Potter RG, Roberts C, Symmons DP, Watson PJ, Torgerson DJ, Macfarlane GJ (2007) Active exercise, education, and cognitive behavioral therapy for persistent disabling low back pain: a randomized controlled trial. Spine (Phila Pa 1976) 32:1578-1585

14. Lamb SE, Hansen ZH, Lall R, Castelnuovo E, Withers EJ, Ichols V, otter R, nderwood MR (2010) Group cognitive behavioural 
treatment for low-back pain in primary care: a randomised controlled trial and cost-effectiveness analysis. Lancet 375:916-923

15. Lambeek LC, van Mechelen W, Knol DL, Loisel P, Anema JR (2010) Randomised controlled trial of integrated care to reduce disability from chronic low back pain in working and private life. BMJ 340:c1035

16. Hall H, McIntosh G (2008) Low back pain (chronic). Clin Evid (Online)

17. Wand BM, O'Connell NE (2008) Chronic non-specific low back pain—sub-groups or a single mechanism? BMC Musculoskelet Disord 9:11

18. Hampel P, Graef T, Krohn-Grimberghe B, Tlach L (2009) Effects of gender and cognitive-behavioral management of depressive symptoms on rehabilitation outcome among inpatient orthopedic patients with chronic low back pain: a 1 year longitudinal study. Eur Spine J 18:1867-1880

19. Henschke N, Ostelo RW, van Tulder MW, Vlaeyen JW, Morley S, Assendelft WJ, Main CJ (2010) Behavioural treatment for chronic low-back pain. Cochrane Database Syst Rev CD002014

20. Poulain C, Kerneis S, Rozenberg S, Fautrel B, Bourgeois P, Foltz V (2010) Long-term return to work after a functional restoration program for chronic low-back pain patients: a prospective study. Eur Spine J 19:1153-1161

21. van Hooff ML, van der Merwe JD, O’Dowd J, Pavlov PW, Spruit M, de Kleuver M, van Limbeek J (2010) Daily functioning and self-management in patients with chronic low back pain after an intensive cognitive behavioral programme for pain management. Eur Spine J 19:1517-1526

22. Roland M, Morris R (1983) A study of the natural history of back pain. Part I: development of a reliable and sensitive measure of disability in low-back pain. Spine (Phila Pa 1976) 8:141-144

23. Ware JE Jr, Sherbourne CD (1992) The MOS 36-item short-form health survey (SF-36). I. Conceptual framework and item selection. Med Care 30:473-483
24. Aaronson NK, Muller M, Cohen PD, Essink-Bot ML, Fekkes M, Sanderman R, Sprangers MA, te Velde A, Verrips E (1998) Translation, validation, and norming of the Dutch language version of the SF-36 Health Survey in community and chronic disease populations. J Clin Epidemiol 51:1055-1068

25. Ehrlich GE (2003) Low back pain. Bull World Health Organ 81:671-676

26. Bertin P, Keddad K, Jolivet-Landreau I (2004) Acetaminophen as symptomatic treatment of pain from osteoarthritis. Joint Bone Spine 71:266-274

27. Huskisson EC (1974) Measurement of pain. Lancet 2:1127-1131

28. von Korff M, Jensen MP, Karoly P (2000) Assessing global pain severity by self-report in clinical and health services research. Spine (Phila Pa 1976) 25:3140-3151

29. Cohen J (1988) Statistical power analysis for the behavioral sciences, 2nd edn. Lawrence Erlbaum Associates, Hillsdale

30. Vlaeyen JW, Kole-Snijders AM, Boeren RG, van Eek H (1995) Fear of movement/(re)injury in chronic low back pain and its relation to behavioral performance. Pain 62:363-372

31. Picavet HS, Vlaeyen JW, Schouten JS (2002) Pain catastrophizing and kinesiophobia: predictors of chronic low back pain. Am J Epidemiol 156:1028-1034

32. Woby SR, Watson PJ, Roach NK, Urmston M (2004) Are changes in fear-avoidance beliefs, catastrophizing, and appraisals of control, predictive of changes in chronic low back pain and disability? Eur J Pain 8:201-210

33. Kerns RD, Habib S (2004) A critical review of the pain readiness to change model. J Pain 5:357-367

34. Nielson WR, Armstrong JM, Jensen MP, Kerns RD (2009) Two brief versions of the multidimensional pain readiness to change questionnaire, version 2 (MPRCQ2). Clin J Pain 25:48-57 